\title{
The Relations Between Physical Exercise and Body Shame among College Students in China
}

\author{
Mengshi $\mathrm{Gu}^{1}$, Xinyi Huang ${ }^{2,}{ }^{*}$, Xiajun $\mathrm{Ye}^{3}$, and Shuning Zhang ${ }^{4}$, \\ ${ }^{1}$ Huanghuai University, Zhumadian, China \\ ${ }^{2}$ Beijing Normal University, Beijing, China \\ ${ }^{3} \mathrm{Xi}$ 'an Jiaotong Liverpool University, Suzhou, China \\ ${ }^{4}$ Chong Qing University of Science and Technology, Chongqing, China \\ These authors contributed equally \\ *Corresponding author. Email: 201811010177@bnu.edu.cn
}

\begin{abstract}
Contemporarily, Chinese college students reduce their satisfaction unconsciously because of the deviation of reality from the ideal with the impact of "standard of beauty". Specifically, anxiety, low self-esteem and lack of confidence, are the expression of body shame may follow. In this paper, we examine the relationship between body shame and physical activity among Chinese college students oriented towards a higher mental health level. As a result of our research, we found that body shame negatively affects physical activity, and that physical activity reduces people's body shame. Through this study, we hope to gain a better understanding of the relationship between body shame and physical activity among university students.
\end{abstract}

Keywords: Body shame, Physical exercise, College students

\section{INTRODUCTION}

In recent years, a series of activities relevant to body shame have arisen, e.g., clavicle coin challenge and A4 waist challenge. These activities, that reflect that the pursuit of beauty is popular among social media in China. Yet, people may feel inferior and diffident on their body when mismatch the expected body shape standard. It was found that body shame often occurs when a person is unable to meet sociocultural or internalized ideals about the body [1]. Meanwhile, Horenstein, et al. mentioned that those people suffering from weight stigma, a form of devaluation are vilified, denigration and stigmatization from those falls within the standard weight and marginalization range [2]. Therefore, many people choose to do physical exercise trying to achieve the "standard of beauty". Different sports are chosen as needed, using a variety of sports means, and combining with natural forces and health measures, in order to build up body, improve health, enhance physical fitness, and adjust the mental status [3]. As a collective activity, physical exercise enhances interpersonal skills, then reducing shame to a certain extent. Thereby, it corrects improve one's body self-esteem and overall self-esteem
[4], i.e., one will increase their self-satisfaction and alleviate their pressure on body.

Grasdalsmoen, et al. demonstrated that more than a quarter of the world's population is failing to meet the recommended level of physical activity and large amount of college students would suffer from a lack of physical activity [5]. Li, Yang \& Yang found that more than one third of students did not engage in sufficient physical activity, while the rest did not engage in sufficient, moderate or vigorous physical activities [6].

It is undeniable that human beings deserve every right to pursue the aesthetic shape, but a judgment on one's appearance regardless of personality is superficial. Therefore, it is important to stop stereotyping the beauty. Lindwall \& Asçi propose that there is a mutual beneficial relationship between exercise and self-perception [7]. In other words, how individuals perceive their bodies and abilities affects their willingness and frequency of exercise and in turn, doing regular workouts has an active impact on how they see themselves [8]. However, few researchers indicate the relations between body shame and physical exercise. Hence, this article focuses on exploring the relations between physical activity and body shame to investigate the impact of body shame on 
physical activity. Besides, we demonstrate the physical activity effect on college students' perceptions of their body. Starting off from the body shame. The article also discusses the feasible way to encourage college students to participate in physical activity.

\section{BODY SHAME}

Shame is a kind of self-conscious and social shaped emotion. It occurs if a behavior is witnessed and negatively evaluated by others when individual acts in a disgraceful way, (e.g., says something unfortunate, or displays a disgraceful or defective characteristic), [9]. Body shame is considered as a component of shame, which refers to the experience of shame when they discover that their bodies do not conform to the ideal standards of beauty defined by society and culture [10]. Body shame originates from not only external (people make a judgment on others) but also internal (starting to view self in the same devaluing manner) [11]. According to the existing definition existing studies of body shame, it can be found that body shame has the two characteristics. First, body shame is a combination of cognition identity and emotional tendency. Secondly, body shame forms in the process of social comparison and influence. Besides, body shame is regarded as a kind of negative cognitional and emotional experience of one's own body in a social situation.

\section{PHYSICAL EXERCISE}

Physical exercise behavior refers to the performance of bodily activities in order to maintain or develop physical fitness and overall health. People need to choose different sports, use a variety of sports means, make full use of leisure time to strengthen physical fitness, enhance physical fitness, adjust their psychological state (Tan \& $\mathrm{Xu}$, 2004) [3]. Its importance had been highly emphasized by many studies that exercise is one of the effective effectively means to enhance the mental health and quality of college students [12].

However, researchers as Xiao \& Cao have found that most undergraduates do not take physical exercises systematically [13]. A variety of reasons contribute to this, including lack of time, partner and sports equipment. It should be noted that lack of time is not the reason for participation in sports activities after graduation. In fact, Weng, Qi \& Tang also mentioned it is related to the state of receiving media sports information and the stage of participation in sports activities [14].

\section{DISCUSSION}

\subsection{Body shame affecting college students regarding physical exercise}

Body shame negatively affects physical activities. Shame is a powerful self-conscious emotion involving a global negative attribution of the self that leads to a desire to hide or escape [15]. Individuals naturally avoid or escape being criticized their bodies.

First, body shame's desire of escaping can make students resistant to change, i.e., unwilling to exercise. In China, women are constantly being exposed to images of idealized bodies, which almost invariably consist of youth, thinness and whiteness [16]. As for college girls, they try to attain this goal. If they fail, they form a negative, shame-filled relationship to their body and to themselves as a person [16]. In order to reduce their own anxiety, this kind of shame will let these students avoid the problem, thus refusing to change. For example, when they need to go to the gym because eating too much, shame lead on avoid exercise for fear of revealing your weight [17]. Besides, physical shame makes them think first about covering up their shortcomings, rather than trying to change them. For example, when college students are dissatisfied with their bodies, they prefer to wear bulky clothes to cover up their shortcomings instead of losing weight by exercise.

Second, body shaming make students more concerned about negative evaluations, which reduces their enthusiasm to participate in physical exercise. For example, weight stigma reduces exercise participation by depriving people of the opportunity to cultivate exercise self-efficacy [2][18]. Brewis proposed a mode of weight stigma that has negative impact on individual's engagement in exercise and other health-seeking behaviours [19]. These results from the feeling judged by others, as well as exclusion from social networks that engage in exercise and/or reduced social support in health behaviour engagement [2]. For example, among college student women (BMI $[\mathrm{kg} / \mathrm{m} 2]=17-38$ ), weight stigma was associated with a greater willingness to avoid exercise. The more negative evaluations they experienced during the day, the higher their body shame and the less time they spent exercising, [20]. Therefore, they would rather stay indoors watching $\mathrm{TV}$ and playing games than do sports because they are afraid of other people's negative comments. Additionally, body shaming is associated with the intensity of college students' physical activity, which is a good point,and will be discussed later.

Third, people with body shame may perceive greater barriers to exercise, and the negative perception accumulates and becomes intense. College students who are unhappy with their bodies may avoid exercise (and interventions to promote it) because they feel they can't 
exercise or cannot have the willpower to keep exercising. Importantly, lack of exercise human beings are not only more likely to perceive obstacles to exercise (e.g., feeling embarrassed or fatigued while exercising), but also less likely to perceive benefits of exercise [21]. Because the long-term lack of exercise, they are unable to accept higher intensity of the movement suddenly (e.g., running, badminton etc). While doing these exercises, their bodies may experience aches and tremors, which can cause them to feel the embarrassment and the shame, i.e., in turn can make them more resistant to exercise.

\subsection{Physical exercise regulate the way college students think of their body}

It has been shown that participating in moderate physical exercise help reduce body shame in several researches. After a period of time practicing yoga, selfobjectification was significant decreased [22], which lessen the sense of body shame [23]. This effect is moderated by the amount of exercise and the type of exercise. It was shown that higher score in exercise ranking, the multiple of exercise intensity and time, a student would feel less body shame [4][24] and more physical self-worth [25].

Exercise can lead to a better mood physiologically, which reduces the emotional experience of shame. Neurophysiological evidence of activity in the frontal cortex during exercise shows the positive effects on one's well-being [26], especially the exercise whose intensities is above ventilatory threshold [27]. In addition to the neurotic pleasure reflection, sports also activate corresponding strategies for regulating negative emotions, for instance, reappraisal [28]. Ligeza et al.'s study showed that the more frequently active the participants were, the larger the reappraisal efficacy they demonstrated with an evidence of the late positive potential [29]. In general, exercise can increase the levels of high-arousal positive (HAP) effect and decrease the level of low-arousal positive affect (LAP) [30][31]. Hence, as a kind of negative feelings, body shame reduces during physical exercise.

Second, participating physical exercise leads to students who become knowledgeable about their own body, which relieves body shame. Body shame is a result from objectification which refers to one's functions are separated out form one's own person [32]. More sports activities will increase the individual's knowledge related to physical activities [33] including sport rules, sports stars, and most importantly, physical fitness. Individuals can view their bodies from a more rational and healthy perspective, which is based on his/she own experience rather than the other's evaluation. Self-objectification is hence reduced, accompanied by the increase of positive emotions (e.g., self-esteem), and the decrease of negative emotions (e.g., body shame) [23].
Third, exercising behaviour can increase one's psychosocial resources for motivating healthy emotions. In physical activities, opportunities to meet more people who keep exercising are increased, especially in sport groups, which increase one's psychosocial resources. Psychosocial resource refers to the totality of the protective and supportive competences used by a person or available to him, which enables external actions [34]. A group of peers with the same exercise goals can provide a better atmosphere in which one can share their anxiety of their bodies and discuss the strategy to release the sense of shame. Moreover, peers' exercising positive behaviours (e.g., perseverance and confidence), are available to other exerciser and influence them by the social learning process [35]. Therefore, the experiences associated with physical activity help one build psychosocial resources [36]. Subsequently, it improves mental health, reduce distress and the sense of shame [24][37][38].

\section{CONCLUSION}

In summary, the relationship between body shame and physical exercise shows that once a college student has felt body shame, he/she is likely to reduce physical exercise which enhances body shame subsequently. Therefore, it is necessary to intervene physical exercise. Here are some recommendations. First, it is important to realize that shying away from changing ourselves has nothing good to get rid of body shame unless people make up their mind to overcome it. In addition, it is necessary to call on people to respect other people's bodies and not to make negative comments about others. According to objectification theory, we can even understand how living in a society that overemphasizes women's physical attractiveness. Besides, relentlessly objectifies can lead to body dissatisfaction and ultimately depression in adolescent girls and women [16]. The last is to have a good physical exercise habit. Gillen found that regardless of actual body shape, those who have a positive physical exercise habit were less likely to adopt unhealthy diets and more likely to try to protect their bodies from sun damage [39]. Furthermore, those with a positive exercise are more likely to have higher selfesteem and were less likely to be depressed [21].

According to our analysis, we demonstrate the mechanics behind body shame hinders physical exercise. Moreover, suggestions are provided to control these factors and reduce the negative effects of body shame on physical exercise. In order to reduce the obstacle of body shame to physical exercise, one can carry out physical exercise more effectively. Interventions to enhance body satisfaction have primarily focused on increasing participants' physical activity, which have had some success, across different types of exercise and groups of individuals [21][40]. These results offer a guideline for people to better understand the relationship between body 
shame and physical activity among Chinese college students.

\section{REFERENCES}

[1] Fredrickson, B. L., Noll, S. M., Roberts, T.-A., Quinn, D. M., \& Twenge, J. M. (1998). That swimsuit becomes you: sex differences in selfobjectification, restrained eating, and math performance. Journal of Personality and Social Psychology, 75(1), 269.

[2] Horenstein, A. , Kaplan, S. C. , Butler, R. M. , \& Heimberg, R. G. . (2021). Social anxiety moderates the relationship between body mass index and motivation to avoid exercise. Body Image, 36, 185192.

[3] Tan, Y. \& Xu, Q. (2004). Study on Influence of Female Undergraduate's Characteristic on Sports Exercise Behaviour. Journal of Xi'an Physical Education University, 6, 109-112.

[4] Song, Z.L. (2008). An investigation on the weakening of college students' sense of shame by physical activity. Modern preventive medicine, 35(17), 3345-3350.

[5] Grasdalsmoen, M., Eriksen, H. R., Lønning, K. J., \& Sivertsen, B. (2020). Physical exercise, mental health problems, and suicide attempts in university students. BMC Psychiatry, 20(1), 1-11.

[6] Li X.X., Yang, H. M. \& Yang Fang. (2018). Influences of Campus Environment on Physical Activity Participation of College Students. Journal of Wuhan Institute of Physical Education, 52(1), 7481.

[7] Lindwall, M., \& Asçi, F. H. (2014). Physical activity and self-esteem. In A. Clow \& S. Edmunds (Eds.), Physical activity and mental health (pp. 83-104). Leeds, UK: Human Kinetics.

[8] Legrand, F., Silete, G., \& Schiffler, F. (2020). Internalized Media-Promoted Body Ideals Only Marginally Moderate the Effects of Exercise on Self-Esteem, Body Image Satisfaction, and Physical Self-Perceptions. Research Quarterly for Exercise and Sport, 91(4), 713-719.

[9] Xu, M. \& Qu C. (2004). A Review of Shame Research. Psychological Science (01), 179-181.

[10] Geng, Y. (2020). Self-objectification and Eating Behavior Problems in College Students: Multiple Mediating Effects of Internalized Body Shame and Externalized Body Shame. Chinese Journal of Clinical Psychology, (02), 364-368+417.
[11] Pinto-Gouveia, J., Ferreira, C., Batista, D. \& Duarte, C. (2015). Body Image as a Source of Shame: A New Measure for the Assessment of the Multifaceted Nature of Body Image Shame. Clinical psychology \& psychotherapy, 22(6), 656-666.

[12] Wang R.L.\& Sun W. (2010). Research on the Influence of Physical Exercises on College Students' Psychological Quality. Inner Mongolia Sports Technology (01), 87-89.

[13] Xiao L. \& Cao Z. S. (2005). Investigation and Research on the Situation of University Students' Physical Exercise and Fitness Needs. Shanxi Sports Technology (03), 48-50.

[14] Weng, X., Qi, L., \& Tang, P. (2021). Research on college students' physical exercise trend based on compartment model. Mathematics and Computers in Simulation, 180, 24-42.

[15] Gilbert, \& Allan. (1998). The role of defeat and entrapment (arrested flight) in depression: an exploration of an evolutionary view. Psychological medicine. Cited from Pila, E. , Gilchrist, J. D. , Huellemann, K. L. , Adam, M. , \& Sabiston, C. M. . (2021). Body surveillance prospectively linked with physical activity via body shame in adolescent girls. Body Image, 36(3), 276-282.

[16] Evans, M. A. (2010). Unattainable Beauty: An Analysis of the Role of Body Shame and SelfObjectification in Hopelessness Depression among College-Age Women. Dissertations \& Theses Gradworks. Cited from Crawford, M. (2012). Transformations: women, gender and psychology. Business \& Economics.

[17] Sabiston, C. , Brunet, J. , Kowalski, K. , Wilson, P. M. , Mack, D. E. , \& Crocker, P. . (2010). The role of body-related self-conscious emotions in motivating women's physical activity. Journal of Sport \& Exercise Psychology, 32(4), 417.

[18] Meadows, A., \& Bombak, A. E. (2019). Yes, we can (no, you can't): Weight stigma, exercise selfeffificacy, and active fat identity development. Fat Studies, 8, 135153.

[19] Brewis, A. A. (2014). Stigma and the perpetuation of obesity. Social Science \& Medicine, 118, 152 158.

[20] Horenstein, A., Kaplan, S. C., Butler, R. M., \& Heimberg, R. G. (2021). Social anxiety moderates the relationship between body mass index and motivation to avoid exercise. Body Image, 36, $185-$ 192. Cited from Vartanian, L. R., \& Shaprow, J. G. (2008). Effects of weight stigma on exercise 
motivation and behavior. Journal of Health Psychology, 13(1), 131-138.

[21] More, K. R., Phillips, L. A. \& Colman, M. H. E. (2019). Evaluating the potential roles of body dissatisfaction in exercise avoidance. Body Image, 28(MAR.), 110-114. Cited from Grubs, L., \& Carter, J. (2002). The relationship of perceived benefits and barriers to reported exercise behaviors in college undergraduates. Family Community Health, 25(2), 76- 84

[22] Cox, A. E., Ullrich-French, S., Cole, A. N. \& D'Hondt-Taylor, M. (2015). The role of state mindfulness during yoga in predicting selfobjectification and reasons for exercise. Psychology of Sport and Exercise, 22, 321-327.

[23] Fredrickson, B. L., \&amp; Roberts, T. A.(1997) Objectification theory: Toward understanding women's lived experiences and mental health risks. Psychology of Women Quarterly, 21(2), 173-206.

[24] Qi, S. (2006). Research on the realtionship between middle schlool students' shame and physical exercise, PhD. Thesis. Shanghai: East China Normal University.

[25] Liu, J. \& Liu, Y. (2010). The relationship between physical exercise and shame, self esteem and social shyness in middle school students. Proceedings of the 9th National Conference on Sports Psychology, 1787-1793.

[26] Schneider, S., Askew, C. D., Diehl, J., Mierau, A. Kleinert, J., Able, H. \& Strüder, H. K. (2009). EEG activity and mood in health orientated runners after different exercise intensities. Physiology \& Behavior, 96, 709-716.

[27] Gaynor, P. \& Gavin, T. (2013). Imagery Use and Affective Responses During Exercise: An Examination of Cerebral Hemodynamics Using Near-Infrared Spectroscopy. Journal of Sport and Exercise Psychology, 35(5), 503-513.

[28] Gross, J. J., \& John, O. P. (2003). Individual differences in two emotion regulation processes: Implications for affect, relationships, and wellbeing. Journal of Personality and Social Psychology, 85(2), 348-362.

[29] Ligeza, T. S., Kalamala, P., Tarnawczyk, O., Macirjczyk, M. \& Wyczesany, M. (2019). Frequent physical exercise is associated with better ability to regulate negative emotions in adult women: The electrophysiological evidence. Mental Health and Physical Activity, 17, 100294.

[30] Hogan, C. L., Mata, J., \& Carstensen, L. L. (2013). Exercise holds immediate benefits for affect and cognition in younger and older adults. Psychology and Aging, 28(2), 587-594.

[31] Magnan, R. E., Kwan, B. M. \& Bryan, A. D. (2013). Effects of current physical activity on affective response to exercise: Physical and social-cognitive mechanisms, Psychology \& Health, 28(4), 418-433.

[32] Bartky, S. L. (1990). Femininity and domination: Studies in the phenomenology of oppression. New York: Routledge.

[33] Brussuau, T. A., Burns, R. D. \& Hannon, J. C. (2016). Effect of Body Composition, Physical Activity, and Aerobic Fitness on the Physical Activity and Fitness Knowledge of At-Risk InnerCity Children. Physical Educator, 73(4), 745-756.

[34] Robitzsch, A., Schweda, A., Hetkamp, M., Niedergethmann, M., Dörrie, N., Herpertz, S., Hasenberg, T., Tagay, S., Teufel, M., \& Skoda, E. M. (2020). The Impact of Psychological Resources on Body Mass Index in Obesity Surgery Candidates. Frontiers in psychiatry, 11, 649.

[35] Bandura, A. (1997) Social Learning Theory. Englewood Cliffs, N.J.: Prentice-Hall.

[36] Hogan, C. L., Catalne, L, I., Mata, J., Fredrickson, B. L. (2015). Beyond emotional benefits: Physical activity and sedentary behaviour affect psychosocial resources through emotions. Psychology \& Health, 30(3), 354-369.

[37] Finkelstein-Fox, L., Groessl, E. J., Elwy, A. R., Lee, S. Y. \& Park, C. L. (2020). Exploring how different types of yoga change psychological resources and emotional well-being across a single session. Complementary Therapies in Medicine, 49, 102354.

[38] Lin, N. \& Ensel, W. M. (2004). Physical fitness and the stress process. Journal of community psychology, 32(1), pp.81-101.Liu, J. \& Liu, Y. (2010). The relationship between physical exercise and shame, self esteem and social shyness in middle school students. Proceedings of the 9th National Conference on Sports Psychology, 1787-1793.

[39] Gillen, M. M. (2015). Associations between positive body image and indicators of men's and women's mental and physical health. Body Image, 13, 67-74.

[40] Hausenblas, H. A., \& Fallon, E. A. (2006). Exercise and body image: A meta-analysis. Psychology \& Health, 21(1), 33-47. 